\title{
Teachers' Experiences in the Development of Digital Storytelling for Cyber Risk Awareness
}

\author{
Fariza Khalid $^{1}$ \\ Faculty of Education, Universiti Kebangsaan Malaysia \\ Bangi, Selangor, Malaysia
}

\author{
Tewfiq El-Maliki \\ Hepia Hes-So \\ Geneva Switzerland
}

\begin{abstract}
Although the Internet has positively impacted people's lives, it also has its dark side. There have been reports on the increase of cases of violence, racial abuse, cyber-bullying, online fraud, addiction to gaming and gambling, and pornography. A vital issue has emerged that Internet users still lack awareness of these online risks. In this study, our respondents were involved in the development of educational videos related to cyber risk topics using a storytelling approach. The participants in this study were 28 in-service teachers who took a master class on Resource and Information Technology. This study aims to examine the issues that participants took into consideration while planning and developing their digital stories, and their experiences developing digital stories about cyber risks. The data was collected using a written reflection. The data was then analyzed thematically using NVivo Software. The findings indicate how the respondents valued their experience in planning, developing, and evaluating their storytelling videos. The impact of learning from the videos on the students' affective domain is also discussed. We further discuss the benefits of the storytelling approach for behavior change.
\end{abstract}

Keywords-Cybersecurity; awareness; education; video; digital storytelling; media; case study

\section{INTRODUCTION}

It is an undeniable fact that the way people learn, retrieve information, and construct knowledge has changed with the existence of the Internet and digital media [1], [2]. Although the Internet is considered the most valuable innovation ever created, it also has a dark side that may result in adverse effects on its users, including adults and children [3]-[5]. Among the potential cyber risks are cybersex [6], pornography [7], personal information exposure [6], [8], [9], cyber addiction [10], online fraud, and addiction to gaming and gambling [11].

Cybersecurity is defined as: "the protection of cyberspace itself, the electronic information, the [Information and Communication Technologies] ICTs that support cyberspace, and the users of cyberspace in their personal, societal and national capacity, including any of their interests, either tangible or intangible, that are vulnerable to attacks originating in cyberspace" [12], [13]. However, the process of cybersecurity has become a more human issue, as it demands a human-centered approach rather than merely technical controls.

According to [14], human weakness is considered the most challenging issue to deal with in relation to cybersecurity. This is because behavior, emotions, and feelings towards technology are somewhat unpredictable [15]. Therefore, to create a safe online environment for all users, everyone must be aware of cyber risks so that early prevention can be done. As the issue of awareness is closely related to the affective domain of learning, it is crucial to have a learning medium that applies an approach that can result in a rise in awareness of the importance of being safe online to avoid such risks. In this study, we launched a project in which digital stories were developed by 28 in-service teachers that covered topics related to cyber risks. This study aims to examine the issues that participants took into consideration while planning and developing their digital stories, and their experiences developing digital stories on cyber risks.

\section{A. Digital Storytelling}

Digital storytelling is an approach that has been found to be engaging for both students and teachers [16]. Storytelling is an approach for communicating information through the use of words, images, and sounds [17], [18]. Although some authors use the word 'narrative' as a synonym for 'story', narratives can be defined as predominantly factual, whereas stories are reflective, creative, and value-laden, usually revealing something important about the human condition [19]. Digital stories can be produced with a combination of visuals, photos, drawings, voice narration, and music to present a narrative [18], and with the existence of multimedia applications, digital stories can be made even more powerful with the integration of the elements such as texts, graphics, audio, video, and animation. In line with this, [18] also points out that digital stories are similar to short films, with a continuous narrative line.

Digital storytelling has potential for learning, as a combination of images, music, narrative, and voice can help promote deep dimensions and vivid colors for characters, situations, experiences, and insights [20], elevating both students' and teachers' experiences [21] and thus accelerating students' comprehension by boosting their interest in discovering new ideas [22]. The use of digital storytelling also helps teachers to build constructivist learning environments that encourage creative problem-solving based on collaboration and peer-to-peer communication [23]. Digital storytelling has been found to facilitate integrated approaches to curriculum development, and to engage learners in higherorder thinking and deep learning [24], creating more engaging and exciting learning environments [25].

The benefits of digital storytelling have not only been reported in relation to the cognitive domain, but it has also 
been shown to be helpful in promoting affective learning. [26], for example, highlights that the use of digital stories can develop a sense of connection among learners and mold their attitudes. This is because, through storytelling, learners will develop their listening skills and be able to identify the key messages of the stories, thus expanding their sense of respect and openness [19].

There are three major categories of digital stories: a) personal narratives-stories that contain accounts of significant incidents in one's life; b) historical documentariesstories that examine dramatic events that help us understand the past; and c) stories designed to inform or instruct the viewer on a particular concept or practice [21]. [27] has formed a comprehensive five-part definition of digital stories: They must a) include a compelling narration of a story; b) provide a meaningful context for understanding the story being told; c) use images to capture and/or expand upon emotions found in the narrative; d) employ music and other sound effects to reinforce ideas; and e) invite thoughtful reflection from their audience(s).

On the other hand, [1] suggests seven elements of digital storytelling: a) the point of view (what is the perspective of the author?); b) a dramatic question (a question that will be answered by the end of the story); c) emotional content (serious issues that speak to us in a personal and powerful way); d) the gift of your voice - a way to personalize the story to help the audience understand the context; e) the power of the soundtrack (music or other sounds that support the storyline); f) economy (simply put, using just enough content to tell the story without overloading the viewer with too much information); and g) pacing (related to economy, but specifically dealing with how slowly or quickly the story progresses).

In this study, the process of developing digital storytelling required teachers who were involved in this project to collaboratively design an educational video using a digital storytelling approach as the end product of the learning process. In this process, they needed to consider themselves as teacher-designers. Participants had to learn specific software skills as and when required by their evolving project. The researchers anticipated that when participants were engaged in their collaborative work, they would develop skills in designing the product, such as how to operate the software needed to develop their animations, video editing, the use of timelines, and how to execute the content to be effectively delivered to end-users. The main role of the instructors was to act as facilitators and problem-solvers, rather than as content experts [28]. Learning in this context involved becoming a practitioner, not just learning about practice [29]. Most importantly, by engaging themselves in the design process, the teachers would build a better understanding of the subject matter, and in how to selecting specific instructional goals instead of general ones. Therefore, according to [28], every act of design is always a process of placing the components of technology, content, and pedagogy together.

\section{MethodolOGY}

This study employed a single case study research design [30]. A case study is an approach that focuses on one or a small number of groups to investigate a contemporary phenomenon within its real context [31], for the purpose of gaining an in-depth understanding of the "events, relationships, experiences or processes occurring in that particular instance" [32, p. 52].

The total number of respondents was 28 teachers, the majority of them are female $(n=24)$, and the rest male $(n=4)$. In terms of their race, the majority was Malay $(n=24)$, while two were Indian, one Chinese, and one Bidayuh, i.e. one of ethnic groups in Sarawak. The participants were masters students who enrolled in an Information and Technology Resources course. However, the subject they were teaching in school varied. As shown in Table I, the largest number were English Language teachers $(n=8)$, followed by Information and Communication Technology $(n=6)$ and Mathematics $(n=5)$; three participants each taught Science and Malay Language, two participants taught Islamic Education, and one participant taught Tamil Language.

The spread of their teaching experience can be seen in Table II. Nine participants had less than three years of teaching experience. The same number had four to nine years of experience, and eight participants had ten to 15 years of experience.

Concerning their former skills in developing digital storytelling, only six of them admitted to having previous skills in this area, while the other 18 had never been involved in digital storytelling. As this project was about spreading awareness of cyber risks, we also asked about their prior involvement in any project related to spreading awareness about cyber risks. However, none of them had ever had experience in this area.

One of the learning outcomes of the course in which the participants were enrolled is that participants be able to produce animated videos using a storytelling approach. As an assessment of this learning outcome, they were challenged to become teacher-designers so as to allow for ownership of their project. The task was for them to plan, design, and develop videos about topics related to cyber risks using any animation software.

TABLE. I. RESPONDENTS' BACKGROUND

\begin{tabular}{|l|l|l|}
\hline Subject taught & $\mathbf{n}$ & \% \\
\hline English Language & 8 & 28.57 \\
\hline Malay Language & 3 & 10.71 \\
\hline Islamic Education & 2 & 7.14 \\
\hline Science & 4 & 14.28 \\
\hline Information and Communication Technology & 6 & 21.42 \\
\hline Mathematics & 4 & 14.28 \\
\hline Tamil Language & 1 & 3.57 \\
\hline
\end{tabular}

TABLE. II. RESPONDENTS' BACKGROUND

\begin{tabular}{|l|l|l|}
\hline Years of teaching experience & $\mathbf{n}$ & \% \\
\hline > 3 years & 9 & 32.14 \\
\hline 4-9 years & 10 & 35.71 \\
\hline $10-15$ years & 8 & 28.57 \\
\hline $18-20$ years & 1 & 3.57 \\
\hline
\end{tabular}


To complete the tasks, they were grouped into groups of four or five, and each group was given a choice of topics to be developed into digital stories. The topics were: a) cyberbullying; b) Internet addiction,; c) pornography; d) games addiction; e) oversharing of personal information; and f) grooming. They were then given the freedom to plan, arrange, and develop the content of their digital stories, starting from developing a storyboard, to developing the animation or video, and designing assessments for after the audience has watched the digital story. Examples of their storyboards are shown in Fig. 1. However, an iterative process also took place through which participants were required to present their storylines to all the members of the group, and received constructive feedback on how to improve their plots. Another presentation took place after they had developed a draft video or animation. Examples of their finalised videos are shown in Fig. 2. At this point, other group members told the developers whether the story had an impact on their feelings. This was a crucial phase, as the aim of the project was to promote awareness, so it was important that the 'audience' felt the message during the preview of the digital stories. The overall process of developing the stories took ten weeks.

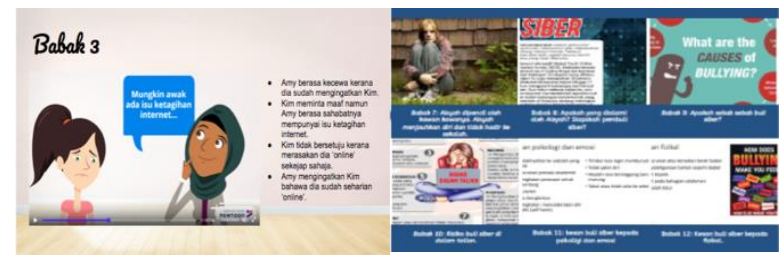

Fig. 1. Examples of Storyboards Developed by the Participants.

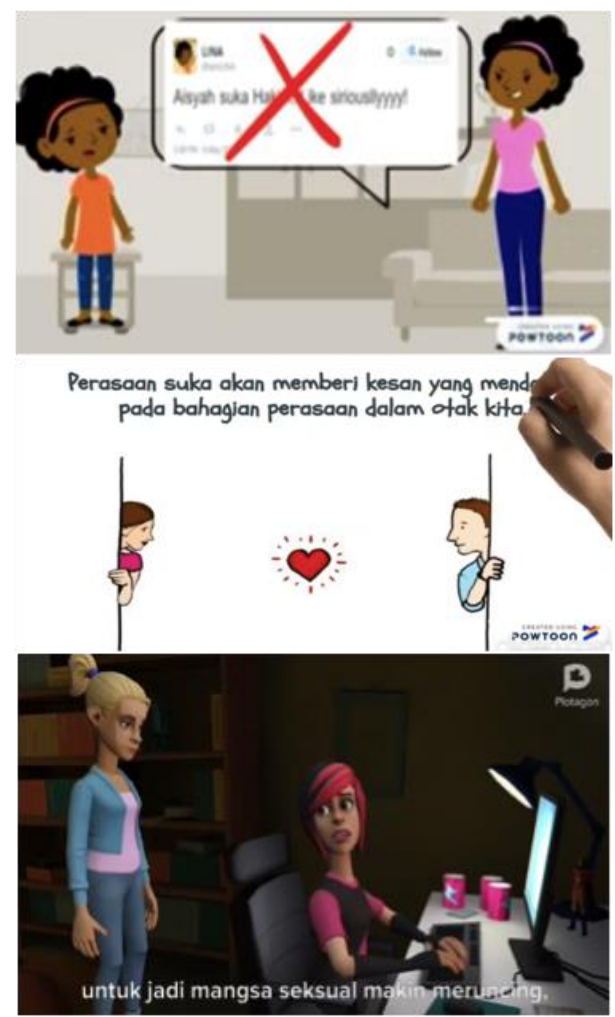

Fig. 2. Examples of Finalised Storytelling Videos Developed by the Participants.
For data collection, we used written reflections (given to the teachers as part of their tasks, and of a minimum of four thousand words) prepared during the final week of the semester. The data was then imported to Nvivo 12 Plus software for coding purposes, and analyzed using thematic analysis [32]. This study aimed to explore the experiences of the participants throughout the whole process as teacherdesigners. Our research questions were:

1) What were the considerations teachers took into account in the development of their digital stories?

2) What are teachers' views on their experiences developing digital stories about cyber risks?

\section{FINDINGS AND DISCUSSIONS}

In this section, we present the findings of the analysis.

Teachers' considerations in the development of digital stories.

The analysis resulted in the emergence of six main themes related to teachers' considerations for the planning, design, and development of their animated videos: a) content; b) characters; c) language; d) narration; e) multimedia elements; and f) duration of the video (see Table III).

1) Content: In terms of the content, as many of the teachers were not very knowledgeable about the topics they were given, the first thing they had to do was to understand the content related to the topic. This included searching for facts available from different sources such as journal articles, books, and websites. As teachers, they were trained to ensure that the delivery of content was based on the facts, and that the arrangement of the information needed to be to suit the level of the target audience, i.e. school students aged from 10 to 14 years old.

Sample statements include: "Since our target audiences are primary and lower secondary school students, we were careful in the selection of the content and the development of the story. We also used simple language to make sure the message is delivered effectively." (Joecy).

"We took many factors into consideration. To make it impactful, we simply provided related facts. We created a storyline to illustrate how a teenager who is addicted to games started to decline in their academic performance, and the deterioration of his health as well. In the end, we showed the dos and don'ts of playing online games." (Ummu).

To enhance the impact of the videos, some of the respondents shared their strategy of developing a storyline that had a similarity to audiences' actual lives.

TABLE. III. TEACHERS' CONSIDERATIONS

\begin{tabular}{|l|l|l|}
\hline Sub-themes & Numbers of participants cited & Percentage \\
\hline Content & 22 & $78.5 \%$ \\
\hline Characters & 18 & $64.2 \%$ \\
\hline Language & 15 & $53.5 \%$ \\
\hline Narration & 13 & $46.4 \%$ \\
\hline Multimedia elements & 24 & $85.7 \%$ \\
\hline
\end{tabular}


"In terms of content delivery, we tried to make our video easy-going for the students. We think that by providing environments similar to their actual lives, it will help to engage them more." (Reene).

For example, for the topic of games addiction, the team members agreed to use PUBG and Fortnite as examples. One of them explained.

"We chose PUBG and Fortnite games in our story. We know that our students love to play these games, so by choosing examples from their real lives may seem more realistic and impactful for them." (Ruhi).

Another respondent also presented an example of how her teammates used examples of students' daily lives in their video.

"Our topic is on grooming. It was a tough topic to be developed as we do not have much information on how it happens in real life, especially in our country. However, I talked to my little sister, and she pointed out the use of WeChat among teenagers, and many of them used the platform to make a connection with adult males. Her friend was once offered a thousand bucks by a man she knew from WeChat if she shared her half-naked picture! So we decided to use that scenario in our video." (Hannah).

The selection of issues related with audiences' actual lives may help them to relate the message to their personal lives and Internet use. Author in [17], in his seven elements of digital storytelling, stresses the importance of personalizing a digital story to help the audience understand the context better.

2) Characters: Participants also pointed out the aspects of the characters that they took into consideration while planning their digital stories. 18 participants mentioned that their group chose to create teenage characters to make their digital stories close to the audiences.

Some of the participants also mentioned they created characters from different races, for instance Malay, Chinese and Indian, as symbols of a multiracial country like Malaysia. For example:

"We wanted the video to have a simple yet powerful message. We chose characters that are similar to their real world. We include characters from different races in our story to promote unity and togetherness as Malaysians as well. We also created characters like counselor, parents, and peers to show who are the significant others for them to turn to if similar case happens to them. " (Shasha).

3) Language: Participants also shared their considerations about the language used in the video. All the groups agreed to use their first language, Malay language, as the medium of their stories. This was decided through discussions among peers in the class. Sample answers include:

"The approach used was very much based on the level of the audience. The narration text was developed according to the pupils' language level. The language chosen was our mother tongue, as it is more familiar to the pupils and thus would help in their total understanding of the story delivered." (Faiza).

The aspect of simplicity, or 'economy' is mentioned by [21] as a vital characteristic of digital storytelling, in that a digital story has to be simply put, using just enough content to tell the story without overloading the viewer with too much information. In addition to the selection of Malay as the language medium, participants also used simple language to suit the level of their target audiences, i.e. students aged from ten to 14 years old. Sample answers include.

"Lastly, we used simple and clear language which is suitable for the level of understanding of primary and secondary school students." (Zaidi)

"Since our target audiences are those in primary and lower secondary school, we were careful in the selection of the content and the development of the story. We also used simple language to make sure the message is delivered effectively. We made it a short and sweet kind of video." (Diane).

Another vital aspect that was taken into consideration was the narration. In order to ensure that the message was successfully delivered, the participants had to choose suitable narrators. Some sample responses include.

"Now that we have developed a script with simple language, there comes a problem. Who is going to be the narrator? It was a funny moment for us when all of us tried to record our voices, and we listened to them together to finally choose the 'best' voice! We are teachers, of course, we have loud voices, but we need to pick the most 'marketable' voice!" (Armie).

"As our digital story uses third-person narration, we need to choose the right voice. We want it to sound pleasant and professional. This is our first baby, so we want to produce the best." (Ila).

4) Narration: In terms of the narration, the majority of the participants used third-person narration. However, several mentioned using first-person narration. For example:

"We agreed to use third-person narration in our story. Our topic is Internet addiction. So our approach is to create a story that includes a self-check approach to help our audience to see whether they count as addicted to the Internet or not. In this case, we think it is better achieved if we use third-person narration." (Kumar)

"Our group used first-person as well as third-person narration. We divided our story into two main sections. The first section was a story of how a girl was bullied by her friends online. The second section included a scene where the girl reflects on how she felt about cyberbullying and what lessons should be learned from her story." (Daisy).

5) Elements of multimedia: As mentioned earlier, this project was about the development of animated videos about cyber risk topics. The participants were empowered to choose any software they preferred to develop their stories. Among the software packages used by the participants were Powtoon, Pixtoon, and Plotagon. Participants also considered aspect of 
multimedia such as audio, music, animation, and colors. The analysis shows that participants agreed on the fact that the use of multimedia elements such as audio, text, graphics, and animation helped them produce better and more impactful learning material. This finding corroborates [18], who also opines that the use of multimedia elements can enhance the power of message delivery. Sample answers include.

"Furthermore, the background music was added to make the video more interesting. We also included the element of feeling. The characters in the story portray feelings to influence the audience or help them relate to the feelings." (Hannah).

"I think what makes the video appealing is because we use animation and music. After getting feedback from peers during the tenth week of class, we got the chance to improve the quality of our music and sound." (Roy).

"The inclusion of recorded audio was also varied according to its suitability for the story in order to give emphasis and highlight important aspects of the story, as well as making the story more interesting for the audience." (Nani).

Digital storytelling has its own potential as a learning material, as a combination of images, music, narrative, and voice can help promote deep dimensions and vivid colors for characters, situations, experiences, and insights [20].

6) Participants' views on their experiences in developing digital storytelling: Based on the overall findings, participants shared their positive thoughts about spreading awareness of cyber risks, especially by using digital stories. 18 participants stated that the approach was a unique way to affect the hearts of the target audiences, compared to giving a lecture or telling them about dos and don'ts. For example, one participant said.

"I am positive that this kind of video can be an effective learning tool for our students. I have tried three videos with my students, who are in Form One [13 years old], and they love it so much. What is important is that we, as teachers, use the material in a meaningful way. Definitely, the video can be used to spur discussion among students, or we can ask them to do some reflections on what they have done in their daily internet use." (Ziana).

This finding is in line with [33], who posits that the use of digital storytelling in class activities can encourage students' insights, and may spur more in-depth discussions. In addition, participants also mentioned that the digital storytelling approach could convey a clear message without burdening learners' cognitive loads: this is because in digital storytelling, other elements of multimedia are used [17]. In this study, the use of animation and narration helped students to gather the information without having to read a dense text. Instead, the videos involved them in thinking about the message and relating it with their own life.

"My reflection on the use of storytelling is that it helps to lessen the cognitive loads of the students, and the presentation of the message can be done more easily with storytelling." (Wani).
Participants in this study also agreed that digital storytelling is an appropriate approach to develop learners' affective domain.

"It [storytelling] can be used to address the affective part of the students. The message in the video is not delivered like a class note; rather, the message is conveyed indirectly through the storyline. It makes learning more fun, too." (Roy).

"We know that from our experience, teaching the affective domain is not easy to achieve. What makes it more challenging is that the affective domain is difficult to assess. You may hear your students say: 'Yes, teacher, I know it is wrong and I can assure you that I will never do such a thing.' Nevertheless, how many of us can guarantee that it will never happen? Hopefully, using digital stories that cater to their affective domain will have an impact on the students." (Daisy).

This finding supports [26], who highlights that the use of digital stories can develop a sense of connection among learners and mold their attitudes. This is because, through storytelling, learners will develop their listening skills and be able to identify the key messages of the stories, thus expanding their sense of respect and openness, and promoting the development of wisdom [19].

"What is beautiful about storytelling is that it helps us to convey the messages more easily in a more powerful way of. Conservatively, we can produce a slide on dos and don'ts. Very dry and monotonous. In contrast, storytelling is more fun to work with. We were challenged to be more creative and more sensitive in the selection of the words and language. This is something that can trigger us, teachers in a school, to learn and do more about the power of storytelling." (Faiza).

Involvement in digital storytelling also made the participants feel engaged in their projects. This supports [16], who claim that digital storytelling is engaging for both learners and teachers.

Other findings derived from the participants' reflections relate to their experiences as teacher-designers. Some of the participants shared that their experiences had been memorable. For example, a number of participants highlighted that through the whole process of developing their digital stories, they had learned many skills, including storyboarding, handling animation software, video editing, voice recording, and decision-making. They explained that the project required higher-order thinking skills, as everything had to be decided among the members of their group. This is closely related to [28]: according to [28], when teachers are given a role as designers, they will develop skills related to what they have been doing. In such situations, teachers have to exercise problem-solving skills and become practitioners [29]. Through their engagement in the design process, teachers will build a better understanding of the subject matter, and learn how to select specific instructional goals instead of general ones [28].

\section{CONCLuSIONS}

In this study, we have examined the considerations that teachers perceived as important while planning and developing their digital stories, and their experiences in 
developing digital stories about cyber risks. Although there are guidelines for digital storytelling, based on the findings, we believe that the considerations are most closely related to the cultural stance of the developers and the targeted audience, for instance in terms of the selection of characters, language, and storyline. This study also further supports the fact that digital storytelling as a powerful technological tool, not only to promote affective learning and positive values, but also to enhance the skills and content knowledge of developers.

\section{ACKNOWLEDGMENTS}

This study was conducted under GG-2019-066 and FRGS/1/2017/SSI09/UKM/02/3 grants.

\section{REFERENCES}

[1] F. Khalid, "Understanding University Students' Use of Facebook for Collaborative Learning", International Journal of Information and Education Technology, vol. 7, no. 8, pp. 595-600, 2017. Available: 10.18178/ijiet.2017.7.8.938.

[2] N. Zakaria and F. Khalid, "The Benefits and Constraints of the Use of Information and Communication Technology (ICT) in Teaching Mathematics", Creative Education, vol. 07, no. 11, pp. 1537-1544, 2016. Available: $10.4236 /$ ce. 2016.711158.

[3] A. A. Karim, P. M. Shah, F. Khalid, M. Ahmad and R. Din, "The Role of Personal Learning Orientations and Goals in Students' Application of Information Skills in Malaysia", Creative Education, vol. 06, no. 18, pp. 2002-2012, 2015. Available: 10.4236/ce.2015.618205.

[4] N. Ahmad, U. A. Mokhtar and Z. Hood, "Cyber Security Situational Awareness among Parents", in Cyber Resilience Conference, Putrajaya, Malaysia, 2019, pp. 7-8.

[5] F. Khalid, M. Y. Daud, M. J. A. Rahman and M. K. M. Nasir, "An Investigation of University Students' Awareness on Cyber Security”, International Journal of Engineering \& Technology, vol. 7, no. 421, pp. 11-14, 2018 [Accessed 1 January 2020].

[6] V. Ratten, "A cross-cultural comparison of online behavioural advertising knowledge, online privacy concerns and social networking using the technology acceptance model and social cognitive theory", Journal of Science and Technology Policy Management, vol. 6, no. 1, pp. 25-36, 2015. Available: 10.1108/jstpm-06-2014-0029.

[7] M. D. Griffiths and D. Kuss, "Online addictions, gambling. video gaming and social networking", in The handbook of the psychology of communication technology, S. Sundars, Ed. Chichester: John Wiley, 2015, pp. 384-406.

[8] L. Mosalanejad, A. Dehghani and K. Abdolahifard, "The Students' Experiences Study", Turkish Online Journal of Distance Education, vol. 15, no. 4, 2014, pp/ 205-216. Available: 10.17718/tojde.02251.

[9] D. Ktoridou, N. Eteokleous and A. Zahariadou, "Exploring parents' and children's awareness on internet threats in relation to internet safety", Campus-Wide Information Systems, vol. 29, no. 3, pp. 133-143, 2012. Available: 10.1108/10650741211243157.

[10] F. Annansingh and T. Veli, "An investigation into risks awareness and e-safety needs of children on the internet", Interactive Technology and Smart Education, vol. 13, no. 2, pp. 147-165, 2016. Available: 10.1108/itse-09-2015-0029.

[11] L. Muniandy and B. Muniandy, "State of Cyber Security and the Factors Governing its Protection in Malaysia", International Journal of Applied Science and Technology, vol. 2, no. 4, pp. 106-112, 2012.

[12] R. Van Solms and J. van Niekerk, "From information security to cybersecurity”, Computers \& Security, pp. 1-6, 2013.
[13] A. Klimburg, National cybersecurity framework manual. Talinn: NATO CCD COE Publications, 2012.

[14] S. Pfleeger and D. Caputo, "Leveraging behavioral science to mitigate cyber security risk", Computers \& Security, vol. 31, no. 4, pp. 597-611, 2012. Available: 10.1016/j.cose.2011.12.010.

[15] M. Bada, A. M. Sasse and J. R. Nurse, "Cyber Security Awareness Campaigns: Why do they fail to change behaviour?", ArXiv, 2014.

[16] Dockter, D. Haug and C. Lewis, "Redefining Rigor: Critical Engagement, Digital Media, and the New English/Language Arts", Journal of Adolescent \& Adult Literacy, vol. 53, no. 5, pp. 418-420, 2010. Available: 10.1598/jaal.53.5.7.

[17] B. Robin, "The Power of Digital Storytelling to Support Teaching and Learning", Digital Education Review, vol. 30, pp. 17-29, 2016.

[18] T. A. Campbell, "Digital Storytelling in an Elementary Classroom: Going Beyond Entertainment", Procedia - Social and Behavioral Sciences, vol. 69, pp. 385-393, 2012. Available: 10.1016/j.sbspro. 2012.11.424.

[19] C. Haigh and P. Hardy, "Tell me a story - a conceptual exploration of storytelling in healthcare education", Nurse Education Today, vol. 31, no. 4, pp. 408-411, 2011. Available: 10.1016/j.nedt.2010.08.001.

[20] M. Razmi, S. Pourali and S. Nozad, "Digital Storytelling in EFL Classroom (Oral Presentation of the Story): A Pathway to Improve Oral Production", Procedia - Social and Behavioral Sciences, vol. 98, pp. 1541-1544, 2014. Available: 10.1016/j.sbspro.2014.03.576.

[21] B. Robin, "Digital Storytelling: A Powerful Technology Tool for the 21 st Century Classroom”, Theory Into Practice, vol. 47, no. 3, pp. 220228, 2008. Available: 10.1080/00405840802153916.

[22] L. Burmark, "Visual presentations that prompt, flash \& transform", Media and Methods, vol. 40, no. 6, pp. 4-5, 2004.

[23] E. Dakich, "From ICT competencies to the social practice of ICT-rich pedagogies: Results of a Delphi study", in Australian Association for Research in Education (AARE) Conference 2004, Melbourne, Australia, 2004.

[24] M. Smeda, E. Dakich and N. Sharda, "Developing a framework for advancing e-learning through digital storytelling", in IADIS International Conference e-learning, Freiburg, Germany, 2010, pp. 169176.

[25] N. Smeda, E. Dakich and N. Sharda, "The effectiveness of digital storytelling in the classrooms: a comprehensive study", Smart Learning Environments, vol. 1, no. 1, 2014. Available: 10.1186/s40561-014-00063.

[26] T. A. Abma, "Learning by Telling", Management Learning, vol. 34, no. 2, pp. 221-240, 2003. Available: 10.1177/1350507603034002004.

[27] B. Alexander, The new digital storytelling. Santa Barbara, Calif: Praeger, 2017.

[28] M. Koehler and P. Mishra, "Teachers Learning Technology by Design", Journal of Computing in Teacher Education, vol. 21, no. 3, pp. 94-102, 2005.

[29] J. S. Brown and P. Duguid, "Organizational Learning and Communitiesof-Practice: Toward a Unified View of Working, Learning, and Innovation", Organization Science, vol. 2, no. 1, pp. 40-57, 1991. Available: $10.1287 /$ orsc. 2.1.40.

[30] M. Denscombe, The good research guide, 4th ed. Maidenhead: Open University Press, 2014.

[31] R. K. Yin, Applications of case study research, 4th ed. Thousand Oaks, CA: Sage, 2009.

[32] V. Braun and V. Clarke, "Using thematic analysis in psychology", Qualitative Research in Psychology, vol. 3, no. 2, pp. 77-101, 2006. Available: 10.1191/1478088706qp063oa.

[33] R. A. Berk, "Teaching strategies for the net generation", Transformative Dialogues: Teaching \& Learning Journal, vol. 3, no. 2, pp. 1-23, 2009. 